IZA DP No. 4870

What Makes a Good Conference?

Analysing the Preferences of Labor Economists

Lex Borghans

Margo Romans

Jan Sauermann

April 2010 


\title{
What Makes a Good Conference? Analysing the Preferences of Labor Economists
}

\author{
Lex Borghans \\ Maastricht University, ROA \\ and IZA \\ Margo Romans \\ ROA, Maastricht University \\ Jan Sauermann \\ ROA, Maastricht University
}

Discussion Paper No. 4870

April 2010

IZA

P.O. Box 7240

53072 Bonn

Germany

Phone: +49-228-3894-0

Fax: +49-228-3894-180

E-mail: iza@iza.org

\begin{abstract}
Any opinions expressed here are those of the author(s) and not those of IZA. Research published in this series may include views on policy, but the institute itself takes no institutional policy positions.

The Institute for the Study of Labor (IZA) in Bonn is a local and virtual international research center and a place of communication between science, politics and business. IZA is an independent nonprofit organization supported by Deutsche Post Foundation. The center is associated with the University of Bonn and offers a stimulating research environment through its international network, workshops and conferences, data service, project support, research visits and doctoral program. IZA engages in (i) original and internationally competitive research in all fields of labor economics, (ii) development of policy concepts, and (iii) dissemination of research results and concepts to the interested public.
\end{abstract}

IZA Discussion Papers often represent preliminary work and are circulated to encourage discussion. Citation of such a paper should account for its provisional character. A revised version may be available directly from the author. 
IZA Discussion Paper No. 4870

April 2010

\section{ABSTRACT \\ What Makes a Good Conference? Analysing the Preferences of Labor Economists ${ }^{*}$}

Conferences are an important element in the work of researchers, requiring substantial investments in fees, travel expenses and the time spent by the participants. The aim of this paper is to identify the preferences of participants with respect to conference characteristics. Based on a sample of European labour economists, preferences are measured using the vignette approach where participants are asked to choose between hypothetical European Association of Labour Economists (EALE) conferences. We find that the keynote speakers are the most important element in the preference for a conference, followed by the location of the conference. There is substantial heterogeneity in the taste of labour economists especially with respect to location, though the link between preference parameters and measured characteristics like gender, age and seniority is limited. Factor analysis suggests that the variety in preferences can be best described by a latent variable that reflects the weights people put on content versus fun.

JEL Classification: A11, J44, C25

Keywords: conference participation, economics profession, vignette-method, random-coefficients model

Corresponding author:

Lex Borghans

Department of Economics

Maastricht University

P.O. Box 616

NL-6200 MD Maastricht

The Netherlands

E-mail: lex.borghans@maastrichtuniversity.nl

\footnotetext{
* The authors thank Eric Bonsang, Didier Fouarge, two anonymous referees, as well as audience at the annual EALE-conference 2009 in Tallinn for helpful discussions.
} 


\section{Introduction}

Attending conferences is an important aspect in the work of researchers. They provide the possibility to acquire feedback on a paper, to get informed about the work of others, and to talk to colleagues to exchange ideas. A relaxed atmosphere and being away from the office can promote creativity. Participating in conferences may even be seen as an attractive part of their labour contract. At the same time, universities regulate conference participation of their researchers with rules for reimbursement of the expenses of conferences. As a consequence, characteristics of conferences like the location, keynote speakers, and possibilities for networking will affect the attractiveness of conferences.

The aim of this paper is to investigate the preferences of economists for conference characteristics empirically. We analyse preferences for conference characteristics using data from a survey held among members of the European Association of Labour Economists (EALE). In order to identify these preferences, we use the vignette method. Respondents were asked to choose six times one out of two hypothetical conferences with randomly varying conference characteristics. We find that keynote speakers are the most important factor for the preference for EALE conferences. Researchers prefer to have more keynote lectures and prefer keynote lectures by Nobel laureates. A conference with two rather than one keynote lecture increases the probability of the conference to be chosen by $10 \%$. A Nobel laureate as keynote speaker further increases this change by $18 \%$. The second most important characteristic is the location of a conference: Barcelona and Oxford are popular locations, conference locations like Uppsala and Frankfurt are less suited to attract researchers. Conference characteristics like the type of social event, the conference venue, and the time of the year are less important in deciding for a conference. When analysing heterogeneity in preferences, we find that there is substantial variation in the preference for number and type of keynote speakers, as well as for the conference location. Researchers differ less in their preference regarding the time of the year. There is no evidence that preferences depend on observable characteristics, such as age, seniority, or gender. 
Like in other economic and non-economic academic disciplines, there is a large number of national and international annual conferences for labour economists, such as the meetings of the Society of Labor Economists (SOLE), the European Society for Population Economics (ESPE), and the EALE. At their meetings, which are usually held at alternating conference locations, one or two renowned economists hold keynote lectures, and often offer formal or informal meetings like conference dinners, receptions, or social activities. Researchers may value conference characteristics differently. Indeed, submission numbers vary considerably over years. A potential determinant of a conference's possibility to attract a large number of submissions in the first place is conference location. Borghans (2003) shows that the attractiveness of a conference location affects the overall number of submissions to a meeting. Yet, it is unclear how researchers value congress location relative to other characteristics.

This paper contributes to the literature on participation in academic conferences. The studies of Borghans (2003) whose analysis is based on information on attendance in previous EALE conferences, and Van Dijk and Maier (2006) who use data from the annual meetings of the European Regional Science Association (ERSA), both analyse the effect of distance to the conference location on participation. Both find that there is a strong tendency to participate in conferences which take place in the home country. Regarding distance to the conference location, Borghans (2003) does not find a significant effect apart from the home country effect. Van Dijk and Maier (2006) suggest a negative effect of distance. They show, however, that there is a difference between frequent and less-frequent conference participants, mainly due to occasional participants from outside of Europe. To the best of our knowledge, there are no other papers aiming at analysing the ranking of characteristics of academic conferences. ${ }^{1}$

The remainder of this paper is organised as follows: we present the vignette approach and the statistical model in the following section. In Section (3), the sample and survey

\footnotetext{
${ }^{1}$ There is a related strand of literature in business studies that focus on touristic characteristics, meeting place facilities, and accessibility of the conference location in attracting conference participants. See e.g. Lee and Back (2007) and the literature cited therein.
} 
design used in this study is described. We discuss estimation results in Section (4). Conclusions are presented in Section (5).

\section{Method}

\subsection{The vignette method}

Vignettes are widely used in marketing research to elicit preferences for product characteristics. A product can be seen as a combination of different attributes that can have different characteristics. A consumer's decision about buying a car may for instance depend on characteristics like the colour and maximum speed. The colour can for instance be blue, red or white, the maximum speed being 140, 160 or $180 \mathrm{~km} / \mathrm{h}$. A consumer attaches a value to each combination of these characteristics. In the same way, conferences can be interpreted as a bundle of different characteristics like conference location, and keynote speakers. Individuals assign different values to each conference, for instance depending on the quality of the keynote speakers, or the attractiveness of the conference location.

Vignettes can best be described as hypothetical situations that can be used "to elicit preferences, judgements, or anticipated behaviour" (McFadden et al. 2005). ${ }^{2}$ In many applications it is impossible to gather data that contains sufficient sets of individuals' choices. The main advantage of using vignettes over standard survey questions is that it allows to take multiple attributes into account and varying them randomly (Wason et al. 2002). This allows to estimate the relative importance of characteristics used. De Wolf and Van der Velden (2001) argue that by presenting characteristics on a vignette simultaneously, the tendency to give social desirable answers is reduced.

In this study, we asked participants of previous EALE-conferences to state their preference for conferences using the vignette method. In order to analyse the valuation

\footnotetext{
${ }^{2}$ For an overview on the use of vignettes for choice experiments, see McFadden et al. (2005). There is also a different application of vignettes in economic research: anchoring vignettes (see e.g. King, Murray, Salomon, and Tandon (2004) and Kapteyn, Smith, and van Soest (2007)). Their studies use vignettes to correct subjective survey response for different perceptions of scales.
} 
of a certain combination of characteristics, each respondent was shown six pairs of vignettes with randomly varying conference characteristics. Each vignette represents one hypothetical conference. From each pair of vignettes, a respondent was asked to choose the preferred one. For each survey participant, all vignettes were generated randomly. We first randomised the order of attributes since it may affect the value attached to a conference attribute. To avoid complexity when rating the vignettes, the order of attributes of the vignettes was randomised at the level of the respondent. The order was thus the same throughout all vignette-questions for a participant. Furthermore, the characteristics of all hypothetical conferences were randomly generated. Each of the two conferences which were shown to survey participants always differed in all their characteristics. Participants thus never had to choose between the same characteristics of one attribute.

Each of the two hypothetical conferences was described by five attributes: the city in which the conference takes places, number of the keynote speaker(s) and whether one is a Nobel laureate, the location of the conference, time of the year, and type of social activities. We assigned up to six different characteristics to each of these attributes. ${ }^{3}$ The main reason to include these attributes is that these are the attributes usually mentioned on the call for papers. There should thus be no other characteristics that may affect the decision to initially submit a paper to the conference. ${ }^{4}$

The characteristics used to measure the effect of the attribute "city" explicitly do not contain a city where a previous EALE-meeting took place. If cities where previous meetings were held would have been included, we could not differentiate whether participants do not prefer this city, or whether they do not want to have a second meeting in the same city. This is also important for the interpretation of our results: while we can interpret the results as preferences for certain conference characteristics, we cannot analyse how preferences change once a researcher attended a conference with certain characteristics.

\footnotetext{
${ }^{3}$ Table 1 shows an example of a vignette question used in the survey. All possible characteristics of the attributes are shown in table 2 .

${ }^{4}$ We held a small pre-test at the annual EALE-meeting 2008 in Amsterdam to check whether the characteristics we selected made sense to participants.
} 
Annual EALE-meetings usually take place in a major European city in September. There are two keynote speakers, one of which is holding the Adam-Smith Lecture. Table 3 shows the characteristics of previous EALE-meetings from 2001 to 2008. The table also shows that the share of papers accepted at as well as the overall number of papers submitted for an EALE meeting varied considerably across years suggesting that conference characteristics affect competition for available presentation slots in the conference. ${ }^{5}$

There are at least two further attributes which could be relevant for submitting a paper to a conference in the first place: reputation of a conference and conference fees. Reputation of a conference and reputation of the association organising the conference may be relevant since attending them may either result in better feedback on own research, networking with more renowned researchers, or attendance may simply act as a signal of own quality. Because the sample is drawn from participants of previous EALEconferences, we particularly asked for deciding between two EALE-conferences in the survey.

Since conference fees should also be affected by the choice of other conference characteristics, such as the venue where the conference takes place, the type of social events, or the profile of the keynote speaker(s), conference fees may be relevant in choosing conferences. For EALE-conferences, however, conference fees are fairly stable across conferences though characteristics differ (see table 3). Partly, this is due to the fact that the conference is co-financed by public and private sponsors. Furthermore, conference fees, but also travel costs, are mostly covered by the institution the participant works for. In the sample used in this study, $78 \%$ of the participants stated that conference fees and travel costs are fully covered when presenting a paper at the conference.

\footnotetext{
${ }^{5}$ There could, however, also be other determinants affecting submissions and acceptance rates, such as conference characteristics of related conferences, and the overall number of available presentation slots.
} 


\subsection{Statistical model}

The choice for conferences made by survey respondents is analysed using a utility maximisation framework. An individual $i$ maximises his utility $U_{i}$ by choosing a conference which is described by attributes $j=1, \ldots, J$. Each attribute can have $N_{j}$ different characteristics $c_{j 1}, \ldots, c_{j N_{j}}$. An individual's utility of conference $k$ depends on the set of characteristics per attribute:

$$
\mathrm{U}_{i k}=U_{i}\left(\mathrm{c}_{k 1}, \ldots, \mathrm{c}_{k J}\right)+\varepsilon_{i k}
$$

$\varepsilon_{i k}$ represents the random part of the valuation that is not accounted for by the observed characteristics. We assume this function to be linear:

$$
\mathrm{U}_{i k}=\sum_{j=1}^{J} \sum_{c=1}^{N_{j}} \alpha_{i j c} d_{k i j c}+\varepsilon_{i k}
$$

where $d_{k i j c}$ is a binary indicator which is 1 if characteristic $c_{k i j}$ describes conference $k$, and 0 otherwise. Difference in utility between two conferences (sets of attributes) $k=A, B$ can be written as

$$
\mathrm{U}_{i A}-\mathrm{U}_{i B}=\sum_{j=1}^{J} \sum_{c=1}^{N_{j}} \alpha_{i j c}\left(d_{A i j c}-d_{B i j c}\right)+\varepsilon_{i A}-\varepsilon_{i B}
$$

An individual will choose conference $A$ when the utility of $A$ exceeds the utility of $B$ $\left(\mathrm{U}_{i A}-\mathrm{U}_{i B}>0\right)$, and vice versa. Equation (3) thus describes a probit model with the difference in utility as a latent variable. The difference $d_{A i j c}-d_{B i j c}$ equals 1 if attribute $j$ on vignette $A$ has characteristic $c,-1$ when this characteristic is on $B$ and 0 if it is neither on $A$ nor on $B$.

We apply different estimation techniques to estimate the preference parameters $\alpha_{i j c}$. First, assuming that all conference participants share the same preference parameters $\left(\alpha_{i j c}=\alpha_{j c}\right)$, we estimate equation (3) non-linearly applying a probit-model. Since regressions are based on 6 observations per individual, standard errors are clustered at the 
individual level. Second, equation (3) is estimated in a random-coefficients framework which allows for heterogeneity of the parameters $\alpha_{i j c}$ (cf. Greene, 2008, p. 728). In the random-coefficients framework parameters are allowed to vary between individuals. We assume the preference coefficients to be normally distributed. This heterogeneity can be identified because respondents were presented 6 choices between two conferences. Assuming individual parameters to be fixed, the standard deviation of the residual $\varepsilon_{i k}$ is estimated based on within-person comparison. Between-person variation then allows us to identify the standard deviation of the choice parameters. In a third step we apply factor analyses to the random coefficients to investigate whether there is a common structure in the random coefficients.

Estimation of the random-coefficients model is numerically burdensome. We therefore estimated this model using a linear specification rather than the probit specification and estimated the models using a structural equation technique in MPlus (Muthén and Muthén, 2008). In this approach, the parameters of the model are estimated by fitting the theoretical matrix of moments in the data to the empirical moments as observed in the data. This approach also allows us to perform factor analyses on the random coefficients simultaneously.

\section{Data}

The survey used in this study was carried out among individuals who participated in at least one of the EALE-meetings in between 2001 and 2008, who could still be contacted by their email-address. In November 2008, 1310 former participants were invited to take part in an online survey. In total, 437 participants filled in the questions on conference participation which corresponds to a response rate of $33.4 \%$.

The average age of respondents is 39 years, $36 \%$ are women (see table 4 ). $49 \%$ of the respondents are in senior positions, such as individuals with a position as (associate) professor, or senior researcher. Junior positions such as PhD-students, post-docs, or assistant professors are held by 41\%. 9\% hold "other" positions. The majority of survey 
participants (91\%) works for an institution in an European country (table 5). The largest share of participants in the survey comes from Germany (16\%), followed by participants from the United Kingdom (11\%) and the Netherlands (9\%). Participants working for a non-European institution amount to $9 \%$ in our sample. In total, the sample covers survey participants from 25 European countries, and 10 countries outside of Europe.

A comparison of EALE-members who participated in our survey and those who did not shows only small differences. For members between 2006 and 2009, the share of women is slightly higher $(37 \%)$ among (previous) EALE members, compared to EALE members who participated in our survey. Age and seniority of EALE-members in general is not known. When comparing countries of residence of survey participants with countries of residence of EALE-members, the data shows only small differences, most notably researchers from Germany are slightly underrepresented among survey-participants. ${ }^{6}$

It is not obvious to define the relevant population for our analysis. In theory, everyone could decide to attend an EALE conference. In practice, there is a core group of labour economists that is very likely to attend and there are labour economists who are less likely to attend the conference. Reasons for that could be that the latter type has a lower attachment to the field, is less interested in EALE or lives outside Europe, etc. If acceptance of a paper depends on its quality, these researchers may submit papers of lower quality. Researchers with a stronger attachment to EALE also have a higher probability to participate in the survey. The relevant population is therefore a gradual concept. We tackle this issue by predicting the probability of participation in the survey based on information on conference attendance in the period 2001 to 2008. By analysing the

\footnotetext{
${ }^{6}$ There is only limited information on members of other (labor) economists association available, either. For the annual meeting of the German economic association, Haufler and Rincke (2009) report that $19 \%$ of all researchers submitting a paper are full professors, compared to $17 \%$ in our sample. They report a share of $23 \%$ women, which is substantially lower compared to participants in our survey (36\%). Using data from a survey held among members of the German economic association in 2006, Frey, Humbert, and Schneider (2007) report that 31\% are younger than 35 (our sample: $29 \%$ ), 54\% (45\%) are older than 34 and younger than 55 , and $16 \%(9 \%)$ are older than 34 .
} 
choices people make separately for more and less attached researchers we can investigate to what extent choices are different for less attached labour economists.

On average, survey participants stated that they participated in three conferences within the 12 months prior to the survey. 59\% of participants attended more than two conferences during this period. After matching survey data to actual participation in EALE-conferences from 2001 to 2008, survey participants turn out to have participated in two previous EALE-conferences on average. Only $24 \%$ participated in more than two conferences.

It is noteworthy mentioning more about the reasons for attending conferences in general, and EALE-conferences in particular: on a 5-point Likert scale, $89 \%$ of survey participants agreed or fully agreed with the statement to participate in conferences in general to get international feedback on their research. ${ }^{7}$ The same share stated to agree with the statement to attend conferences for networking purposes. At the same time, $33 \%$ are attending conferences for fun. Corresponding numbers for EALE-conferences in particular are slightly lower compared to the numbers for conferences in general.

In general, participants indicate in these survey questions that they prefer attractive conference locations (61\%) and easy-to-reach places (80\%). Travel costs play a minor role for conferences: $57 \%$ agree with the statement that travel costs should be low. At the same time, travel expenses are mostly fully covered by the institution a researcher works for if the participant is accepted for presenting a paper (78\% of all respondents).

\section{Estimation results}

\subsection{Homogenous preferences}

An individual's decision for a conference $A$ or $B$ is analysed by estimating equation (3). Columns (1) and (2) of table 6 show the results of a probit model estimating pa-

\footnotetext{
${ }^{7}$ This and the following variables are measured on a 5-point Likert scale with the values "fully disagree", "disagree", "undecided", "agree", and "fully agree".
} 
rameters $\alpha_{j c}$ which are assumed to be constant across individuals. For each attribute the characteristic that is preferred least is used as reference category.

The importance of conference attributes can be compared in several ways. Comparing the difference of the largest and the smallest coefficient of the characteristics, keynote speakers turn out to be the most important determinant. Looking at the difference between characteristics, the difference between a conference with and without a Nobel prize winner is also larger than other differences. Furthermore, researchers prefer two keynotes speakers compared to one. But in both cases the additional effect of a Nobel prize winner as a keynote speaker is substantially higher than any other difference. An important question is whether researchers value the perceived quality of a Nobel prize winners as keynote speaker, whether they are just curious to see these famous economists, or whether a good keynote speaker may attract other conference participants of a higher quality.

The second most important attribute for choosing a conference is the city in which the meeting takes place. Compared to the reference category, a conference in Uppsala, the most popular conference location is Barcelona, closely followed by Oxford. Budapest and Malta are still popular locations, though to a lower extent. Frankfurt is not significantly different from the least popular conference, Uppsala.

While the results show a clear ranking of the cities used in the vignettes, it is not clear whether and how preferences change if one of the previous meetings already took place in one of the cities mentioned. The same argumentation does hold for keynote speakers: if one keynote-speaker is invited in one year, the preference for this keynote speaker may indeed be lower in the following years. Since the characteristics for keynote speakers used in the vignette are general, this dynamic effect should affect the results for type and number of keynote speakers.

Conference location and type of keynote speakers are by far the most important attributes of a preferred conference. Other conference attributes are relevant for decisions, but to a smaller extent: researchers prefer an informal garden barbecue instead of more formal events like formal dinners or a reception in the city hall. 
Regarding time of the year, researchers prefer September. Similarly important is the venue of the conference: researchers prefer a conference in a university, rather than in a hotel. These two results could reflect habits, since almost all EALE-conferences took place in a university in September. The preference for September could also be related to the timing of other conferences. Implicitly, our approach keeps the timing of other conferences constant.

Based on information about conference participation in the period 2001 to 2008 we predict the probability that people who were invited for the survey actually responded. This regression included dummies for each conference and the total number of conferences attended and its square. The predicted probability of participating in the survey is not related to the characteristics, such as seniority or socio-economic characteristics of individuals.

In order to investigate whether strongly attached researchers differ in their taste from less attached researchers, we split the sample in two parts, below and above the median probability (.309). Only the parameters for the keynote speakers turn out to be significantly smaller for the stronger attached respondents. ${ }^{8}$ A similar analysis using the probability to attend a conference gives similar results. This result implies that keynotes are more important for conference participants who are on the margin of attending a conference.

A potential concern about the vignette method is the design of the vignettes in the survey. Decisions about attending conferences may depend on the ordering of the attributes in the vignettes. For analysing this, we randomised the order of attributes at the level of the individual. All vignettes for one individual were thus shown in the same order. Including the order of attributes into our regression analysis, however, did not turn out to significantly affect our results. Furthermore, respondents may answer the first pairs of vignettes different than the last pairs of vignettes, for instance due to fatigue. Again,

\footnotetext{
${ }^{8}$ The results of this estimation are not shown but are available upon request from the authors.
} 
our robustness analysis did not show any effects of the position of a specific vignette in the survey completed by participants.

\subsection{Varying preference parameters}

In a second step, equation (3) is estimated in a random-coefficients framework. The random-coefficients model allows to analyse heterogeneity in estimated parameters. This model is estimated linearly for computational reasons. Columns (3) and (4) provide the estimates of a linear specification without random coefficients to facilitate comparison. The coefficient mean (column (5)) and its standard error (6) of table 6 show that the main results about the importance of conference attributes and its characteristics are the same as in the probit model with non-varying estimated parameters. Columns (7), which shows the estimated standard deviation of the parameters $\alpha_{i j c}$, and (8) of table 6 , however, provide evidence that there is substantial heterogeneity in estimated parameters between individuals.

Among the locations especially the standard deviations of Budapest, Frankfurt and Malta are large in comparison with the mean. This suggests that although on average participants prefer these locations to Uppsala, there is also a group of participants who rank these cities in a different order. When assuming normally distributed coefficients $\alpha_{i j c}$, and taking into account the correlation between these parameters we find that for $2.1 \%$ of the sample Barcelona is the least attractive place. For Oxford this is $0.5 \%$.

The same holds for conferences with two keynote speakers. On average people prefer two keynotes above one, but a substantial fraction of the participants prefers one keynote. Most participants prefer a keynote speech by a Nobel laureate, independently whether there are one or two keynote speeches in total.

While there is some heterogeneity in the characteristic of whether the conference should take place in September, there is no evidence for significant variation in social events, and the conference venue. 
Observable characteristics such as gender, age, and seniority may matter for the decision to attend conferences as well. In order to evaluate whether coefficients depend on these characteristics, we allowed the random coefficients to be a function of observable characteristics. Only a few estimates for the covariates, however, are significant. The position of a researcher plays a minor role when it is about preference for keynote speakers. ${ }^{9}$ Though there is substantial variation in the taste of labour economists, observable individual characteristics seem hardly to be relevant when choosing for conferences.

\subsection{Factor-analysis}

Though individual characteristics play a minor role for estimated parameters, the standard deviations of the random parameters reveal that there is a large heterogeneity in the preference for conference characteristics. In order to analyse this heterogeneity of preferences in greater detail, we applied factor analysis to the random coefficients. The factor loadings of the common factor $f$ are shown in table 7 . This factor seems to create a scale of people who choose the conference based on the location, versus people who are looking for content. Location contributes most to the variation in the latent factor $f$. Barcelona, Budapest, Malta and conferences in June are positively related to $f$. In contrast, two keynote speakers without Nobel laureate are negatively related. When relating the factor $f$ to individual characteristics, the results show no correlation. There appears, however, to be a strong relationship between the latent factor and answers to statements about conference participation made in the survey. The factor $f$ is positively related to agreement with the survey questions whether it is important that "a conference takes place in an attractive place", whether "conferences are attended to relax from work", and whether one's "employer supports conference participation as a reward for good effort". ${ }^{10}$ The positive correlation between the factor $f$ and the answers to these

\footnotetext{
${ }^{9}$ The results of the random-coefficient model with covariates are not shown, but are available upon request.

${ }^{10}$ The answers to these statements were measured on a 5 -point Likert scale, where 1 is "strongly disagree", and 5 "strongly agree".
} 
statements underlines the basic result from the factor analysis which suggested that there are people weighting attractive places more, while others are more looking for content.

Having these findings in mind, the question is whether there is an optimal conference an association could design in order to attract a large number of potential researchers. Based on the individual estimated coefficients, we calculated the most popular conferences for our sample. The most popular conference has the following characteristics: Barcelona, 2 keynote speakers (including one Nobel laureate), informal garden barbecue, September, university. If two conferences could be organised to give people choice and therefore increase total utility a second conference would be identical to the first one except for its location Oxford.

Varying the latent variable $f$ we find that respondents with a low value of $f$, i.e. those who prefer content over ambiance, prefer this Oxford conference. Respondents with a more average value of $f$ prefer the Barcelona conference with otherwise the same characteristics. People with high value's of $f$ would prefer a similar Barcelona conference in June. Figure 1 shows the distribution of the latent variable of the respondents who would choose each of these three conferences if they could choose out of this set of three.

\section{Conclusion}

Conferences are an important element in the work of researchers, requiring substantial investments in fees, travel expenses and the time spent by the participants. The aim of this paper was to identify the preferences of participants with respect to the characteristics of a conference. Using information from a survey among EALE-members, we measured preferences by exploiting researchers' decisions about hypothetical conferences.

Keynote speakers and conference location are the most important attributes to decide for a conference, while the remaining attributes type of social event, time of the year, and conference venue are less important for the decision. Researchers prefer more than two keynote lectures and keynote-lectures by a Nobel laureate. This effect is stronger for participants with a lower attachment to EALE conferences. 
The results of the random-coefficients model show that there is substantial variation in the taste of labour economists: while some conference characteristics are preferred to others when evaluated at the coefficient mean, it is also important to look at the share of individuals who disagree with a specific conference characteristic. Despite the substantial variation in estimated preference parameters, the link between preferences parameters and measured characteristics like gender, age and seniority is limited.

Factor analysis suggests that there is variety in the preference for "content versus attractive places". Location is responsible for most of the variation of this latent factor. For that reason, if two rather than one conference would be organised simultaneously, the utility maximising set would only differ in location.

The paper shows that varying characteristics of a conference can influence both the overall attractiveness of a conference, but also influences the type of researchers interested in participation. Selecting these characteristics is therefore a strategic instrument for scientific associations to reach their goals.

This paper aimed at looking at preferences of conference participation. In future research more detailed aspects of researchers preferences could be investigated. Furthermore, more research needed on the role of conference in researcher's careers. Two important questions are: what does selection into submission and acceptance determine? Is it quality? Furthermore, it is important to look at the role of participation and presentation at conferences. Does participation increase career possibilities? Or do better (labour) economists (not) attend conferences? 


\section{References}

Borghans, L. (2003): "Why do researchers go to a conference?," Discussion paper, Research Centre for Education and the Labour Market (ROA), Maastricht University, mimeo.

De Wolf, I., And R. VAn Der Velden (2001): "Selection Processes for Three Types of Academic Jobs: An Experiment among Dutch Employers of Social Sciences Graduates," European Sociological Review, 17(3), 317-330.

Frey, B. S., S. Humbert, And F. S. Schneider (2007): "Was denken deutsche Ökonomen? Eine empirische Auswertung einer Internetbefragung unter den Mitgliedern des Vereins für Socialpolitik im Sommer 2006," Perspektiven der Wirtschaftspolitik, 8(4), 359-377.

Greene, W. H. (2008): Econometric Analysis. Prentice Hall, Upper Saddle River, NJ, 6 th edn.

Haufler, A., And J. Rincke (2009): "Wer trägt bei der Jahrestagung des Vereins für Socialpolitik vor? Eine empirische Analyse," Perspektiven der Wirtschaftspolitik, 10(2), $123-145$.

Kapteyn, A., J. P. Smith, and A. van Soest (2007): "Vignettes and Self-Reports of Work Disability in the United States and the Netherlands," American Economic Review, 97(1), 461-473.

King, G. A., C. Murray, J. Salomon, and A. Tandon (2004): "Enhancing the Validity and Cross-Cultural Comparability of Measurement in Survey Research," American Political Science Review, 98(1), 191-207.

LeE, M. J., AND K.-J. BACK (2007): "Effects of Destination Image on Meeting Participation Intentions: Empirical Findings from a Professional Association and its Annual Convention," The Service Industries Journal, 27(1), 59-73. 
McFadden, D., A. Bemmaor, F. Caro, J. Dominitz, B.-H. Jun, A. Lewbel, R. Matzkin, F. Molinari, N. Schwarz, R. Willis, and J. Winter (2005): "Statistical Analysis of Choice Experiments and Surveys," Marketing Letters, 16(3), 183-196.

Muthén, L., And B. MuthÉn (2008): Mplus User's Guide. Muthen \& Muthen, Los Angeles, CA, 5 edn.

VAN DiJK, J., AND G. MAieR (2006): "ERSA Conference participation: does location matter?," Papers in Regional Science, 85(4), 483-504.

Wason, K. D., M. J. Polonsky, and M. R. Hyman (2002): "Designing Vignette Studies in Marketing," Australasian Marketing Journal, 10(3), 41-58. 
Table 1: Hypothetical vignette-question

Suppose you could choose one of these two EALE conferences

\begin{tabular}{|l|l|l|}
\hline & Option A & Option B \\
\hline $\begin{array}{l}\text { City } \\
\text { Keynote speaker(s) }\end{array}$ & $\begin{array}{l}\text { Budapest } \\
\text { One keynote speaker }\end{array}$ & $\begin{array}{l}\text { Uppsala } \\
\text { Two keynote speakers } \\
\text { (where one is Nobel lau- } \\
\text { reate) }\end{array}$ \\
$\begin{array}{l}\text { Social activities } \\
\text { Time of year }\end{array}$ & Barbecue & Formal dinner \\
Congress location & June & Oniversity \\
\hline
\end{tabular}

which one would you choose?

\section{Option A Option B}

Table 2: Conference characteristics used for generating vignettes

\begin{tabular}{l|l}
\hline \hline Attribute & characteristics \\
\hline City & $\begin{array}{l}\text { Barcelona; Budapest; Uppsala; Oxford; Frank- } \\
\text { furt; Malta } \\
\text { One keynote speaker; two keynote speakers; one } \\
\text { keynote speaker (Nobel laureate); two keynote } \\
\text { speakers (where one is Nobel laureate) }\end{array}$ \\
Social activities & $\begin{array}{l}\text { Formal dinner; informal garden barbecue; recep- } \\
\text { tion city hall } \\
\text { Time of year }\end{array}$ \\
Congress location & \begin{tabular}{l} 
Hotel; university \\
\hline
\end{tabular}
\end{tabular}




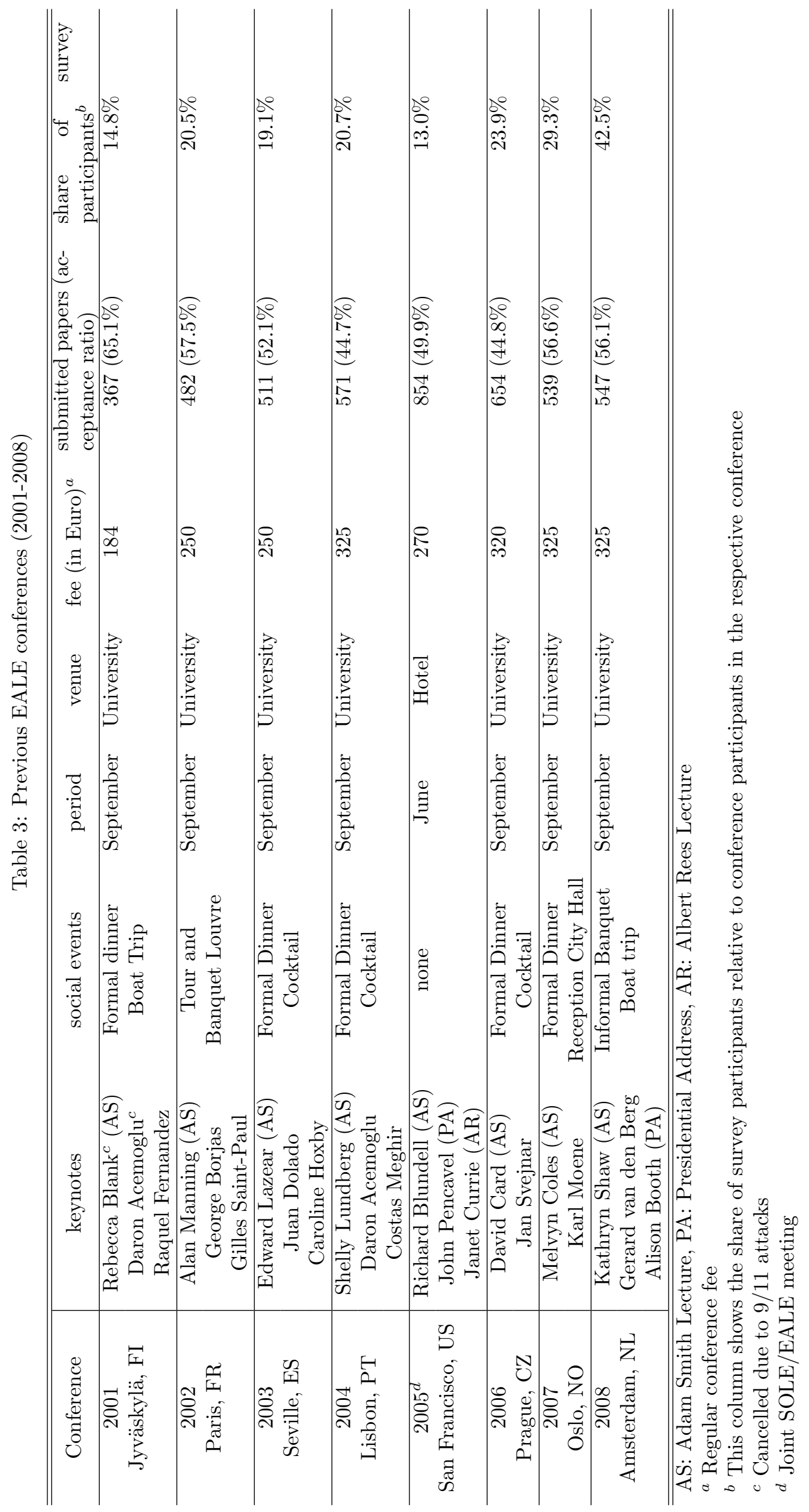


Table 4: Summary statistics $(N=437)$

\begin{tabular}{lc}
\hline \hline & mean \\
\hline Age & 39.15 \\
Gender $(1=$ female $)$ & 0.36 \\
Children $(1=$ yes $)$ & 0.52 \\
Senior position & 0.49 \\
Junior position & 0.41 \\
Other position & 0.09 \\
Number of EALE conferences $(2001-2008)$ & 1.69 \\
Number of conferences last year & 3.15 \\
\hline \hline
\end{tabular}

Table 5: Working country of survey participants $(N=437)$ and EALE-members 2006-2009 $(\bar{N}=377)$

\begin{tabular}{lcc}
\hline \hline & mean (survey) & mean (EALE-members) \\
\hline Austria & 0.01 & 0.01 \\
Belgium & 0.02 & 0.02 \\
Denmark & 0.05 & 0.05 \\
Finland & 0.04 & 0.04 \\
France & 0.08 & 0.09 \\
Germany & 0.16 & 0.20 \\
Italy & 0.08 & 0.07 \\
Netherlands & 0.09 & 0.08 \\
Norway & 0.04 & 0.05 \\
Portugal & 0.02 & 0.01 \\
Romania & 0.01 & 0.01 \\
Spain & 0.06 & 0.05 \\
Sweden & 0.07 & 0.07 \\
Switzerland & 0.03 & 0.02 \\
United Kingdom & 0.11 & 0.10 \\
Other European countries & 0.04 & 0.04 \\
Non-European countries & 0.09 & 0.07 \\
\hline \hline
\end{tabular}


Table 6: OLS, probit and random coefficient estimates

\begin{tabular}{|c|c|c|c|c|c|c|c|c|}
\hline & \multicolumn{2}{|c|}{ Probit } & \multicolumn{2}{|c|}{ OLS } & \multicolumn{4}{|c|}{$\begin{array}{l}\text { Random coefficients model (linear) } \\
\end{array}$} \\
\hline & (1) & (2) & (3) & $(4)$ & $(5)$ & $(6)$ & (7) & $(8)$ \\
\hline & est. & S.E. & est. & S.E. & coef. mean & S.E. & coef. SD & S.E. \\
\hline \multicolumn{3}{|c|}{ Conference location (reference: Uppsala) } & & & & & & \\
\hline Barcelona & $0.513^{* * *}$ & $(0.063)$ & $0.178^{* * *}$ & $(0.021)$ & $0.175^{* * *}$ & $(0.021)$ & $0.114^{* *}$ & $(0.058)$ \\
\hline Budapest & $0.196^{* * *}$ & $(0.065)$ & $0.068^{* * *}$ & $(0.023)$ & $0.068^{* * *}$ & $(0.022)$ & $0.152^{* * *}$ & $(0.046)$ \\
\hline Frankfurt & 0.018 & $(0.061)$ & 0.005 & $(0.021)$ & 0.006 & $(0.021)$ & $0.161^{* * *}$ & $(0.045)$ \\
\hline Malta & $0.180^{* * *}$ & $(0.061)$ & $0.061^{* * *}$ & $(0.021)$ & $0.066^{* * *}$ & $(0.021)$ & $0.145^{* * *}$ & $(0.052)$ \\
\hline Oxford & $0.382^{* * *}$ & $(0.062)$ & $0.132^{* * *}$ & $(0.021)$ & $0.131^{* * *}$ & $(0.021)$ & $0.118^{* *}$ & $(0.059)$ \\
\hline \multicolumn{3}{|l|}{ Keynotes (reference: 1 speaker) } & & & & & & \\
\hline 1 speaker (Nobel laureate) & $0.464^{* * *}$ & $(0.050)$ & $0.165^{* * *}$ & $(0.017)$ & $0.162^{* * *}$ & $(0.017)$ & $0.114^{* *}$ & $(0.045)$ \\
\hline 2 speakers & $0.291^{* * *}$ & $(0.046)$ & $0.102^{* * *}$ & $(0.016)$ & $0.099 * * *$ & $(0.016)$ & $0.110^{* *}$ & $(0.044)$ \\
\hline 2 speakers (incl. 1 Nobel laureate) & $0.788^{* * *}$ & $(0.051)$ & $0.280^{* * *}$ & $(0.016)$ & $0.279^{* * *}$ & $(0.016)$ & 0.078 & $(0.068)$ \\
\hline \multicolumn{3}{|c|}{ Social event (reference: formal dinner) } & & & & & & \\
\hline Informal garden barbecue & $0.152^{* * *}$ & $(0.038)$ & $0.053^{* * *}$ & $(0.013)$ & $0.052^{* * *}$ & $(0.013)$ & .063 & $(0.073)$ \\
\hline Reception city hall & 0.063 & $(0.039)$ & $0.022^{*}$ & $(0.013)$ & 0.020 & $(0.013)$ & 0.078 & $(0.049)$ \\
\hline \multicolumn{3}{|l|}{ Month (reference: October) } & & & & & & \\
\hline May & 0.042 & $(0.045)$ & 0.014 & $(0.016)$ & 0.014 & $(0.016)$ & 0.071 & $(0.066)$ \\
\hline June & 0.030 & $(0.045)$ & 0.010 & $(0.016)$ & 0.012 & $(0.015)$ & 0.078 & $(0.062)$ \\
\hline September & $0.134^{* * *}$ & $(0.048)$ & $0.045^{* * *}$ & $(0.017)$ & $0.052^{* * *}$ & $(0.016)$ & $0.110^{* *}$ & $(0.048)$ \\
\hline \multicolumn{3}{|l|}{ Venue (reference: hotel) } & & & & & & \\
\hline University & $0.150^{* * *}$ & $(0.027)$ & $0.053^{* * *}$ & $(0.009)$ & $0.050^{* * *}$ & $(0.009)$ & 0.055 & $(0.049)$ \\
\hline Constant & 0.027 & $(0.027)$ & $0.490^{* * *}$ & $(0.009)$ & $0.493^{* * *}$ & $(0.009)$ & 0.374 & $(0.024)$ \\
\hline \multicolumn{3}{|l|}{$\chi^{2}$-test $(14)$} & \multicolumn{2}{|c|}{$398.7^{* * *}$} & & & & \\
\hline Individuals & \multirow{2}{*}{\multicolumn{2}{|c|}{$\begin{array}{c}420 \\
2519\end{array}$}} & \multirow{2}{*}{\multicolumn{2}{|c|}{420}} & \multicolumn{4}{|c|}{420} \\
\hline Observations & & & & 2519 & \multicolumn{4}{|c|}{2519} \\
\hline
\end{tabular}

${ }^{*} p<0.10,{ }^{* *} p<0.05,{ }^{* * *} p<0.01$

Clustered standard errors in parentheses 
Table 7: Factor analysis

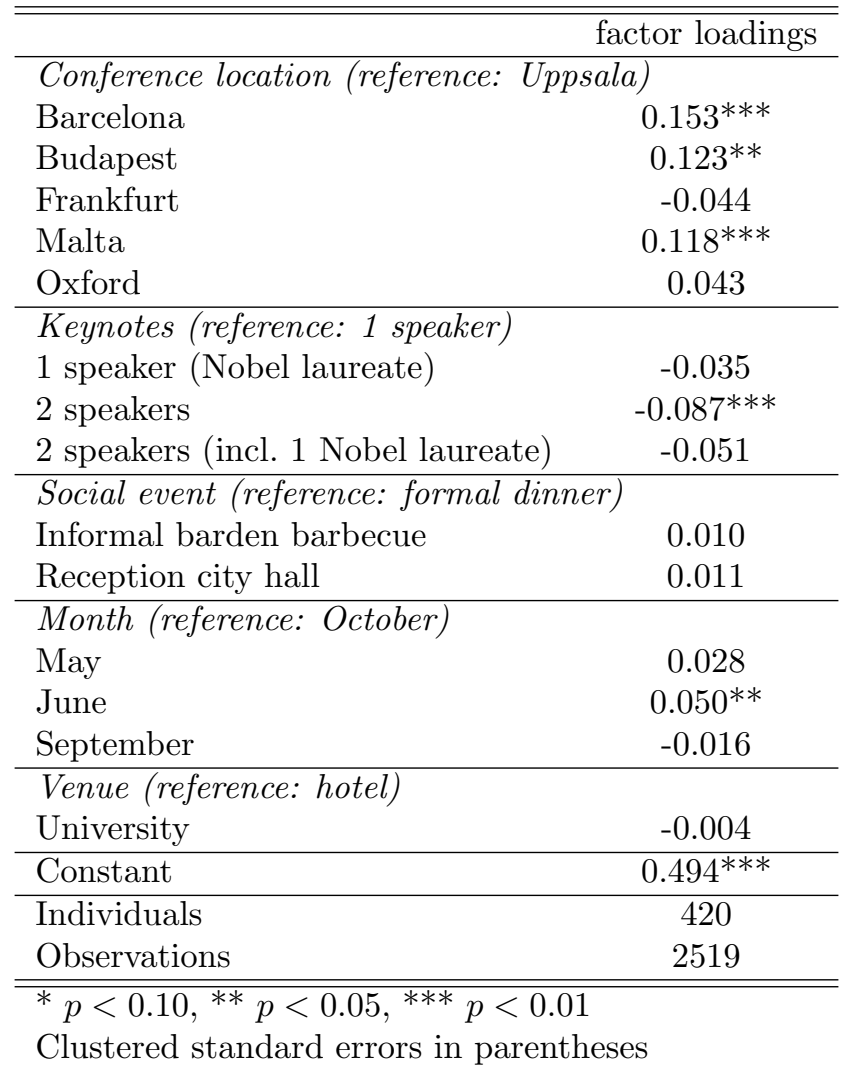


Figure 1: Distribution of the latent variable $f$ of the respondents who choose one of the three most popular conferences

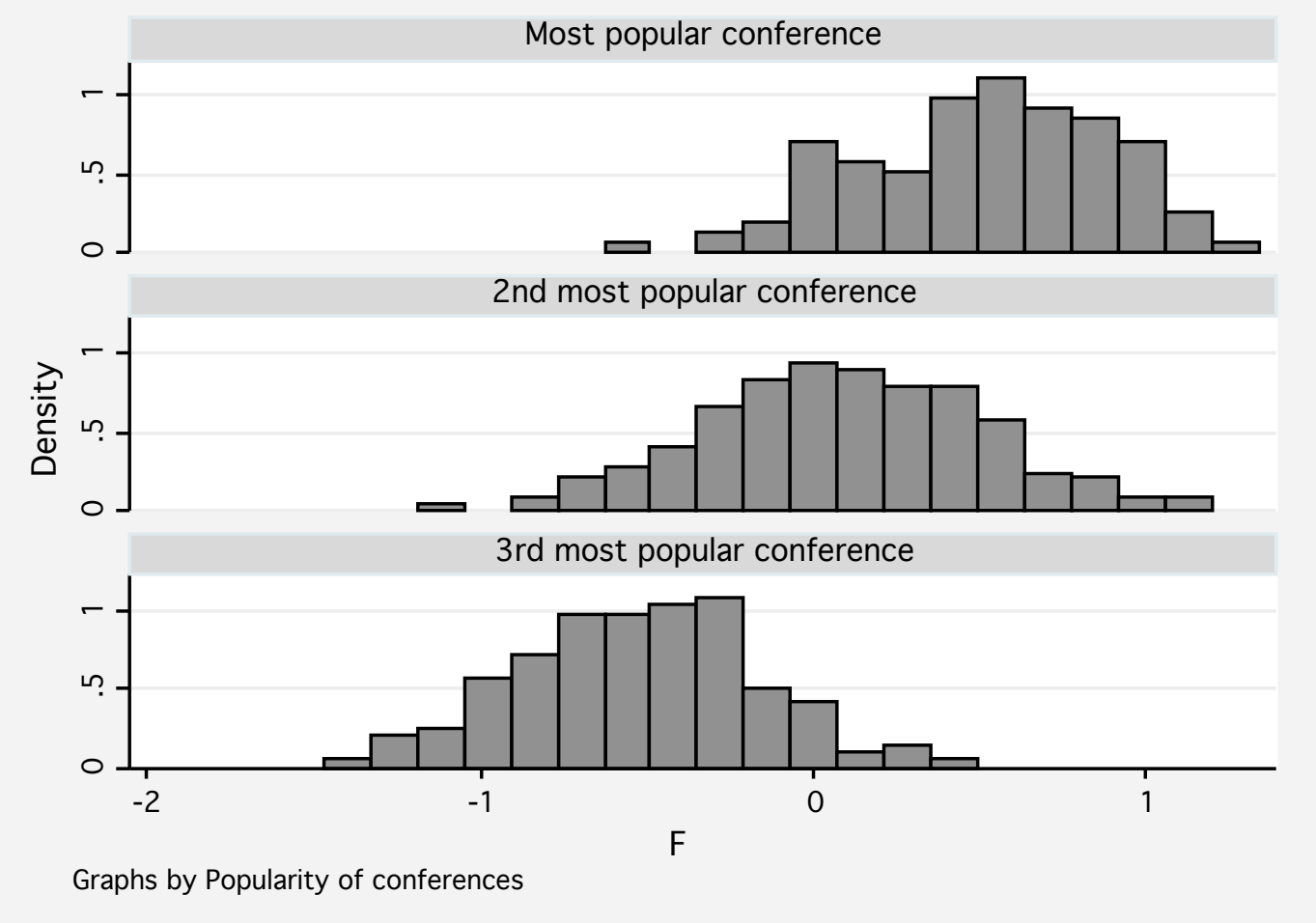

